\section{Ph value of infant's skin is higher on diaper area compared to nondiaper area}

\author{
Nadia Wirantari, Linda Astari, \\ Iskandar Zulkarnain \\ Department of Dermatoveneorology, \\ Medicine Faculty of Airlangga \\ University/Dr. Soetomo Hospital, JI. \\ Mayjen Prof. Dr. Moestopo No 6-8 \\ Surabaya, Indonesia
}

\begin{abstract}
Prolonged use of diaper may alter skin barrier function due to exposure to irritants from feces and urine, concurrent mechanical friction and occlusion, thus render the skin prone to inflammation and infection. Measurement of skin $\mathrm{pH}$ value may be used to document skin barrier function, especially in tropical countries such as Indonesia, and to expose the difference between diapered and non-diapered skin. The purpose of this study is to compare the $\mathrm{pH}$ value between baby's diapered and non-diapered skin. In this cross-sectional study, the skin $\mathrm{pH}$ of 43 healthy babies aged 6 to 12 months were measured using $\mathrm{pH}$-meter on diaper and non-diaper area of the skin. $\mathrm{pH}$ values were documented and compared. The mean $\mathrm{pH}$ value of diaper area was 6,11 $\pm 0,72 \mathrm{~g} / \mathrm{m}^{2} / \mathrm{h}(95 \% \mathrm{CI}, 4,88-8,02)$ and non-diaper area was $5,91 \pm 0,69 \mathrm{~g} / \mathrm{m}^{2} / \mathrm{h}$ (95\% CI, 4,53 - 7,69), with significant difference $(p=0,005)$. $\mathrm{pH}$ values increased significantly on diaper area compared to nondiaper area, revealing impaired barrier function on diapered skin, despite no pathological skin changes.
\end{abstract}

\section{Introduction}

The use of diaper has become a necessity in infant care, and is an important factor influencing skin barrier function. In the Asia Pacific, the market for disposable diapers in 2013 is over $60 \%{ }^{1}$ Prolonged use of diaper may cause increased $\mathrm{pH}$ value due to occlusion by urine and feces. An acidic skin is necessary to maintain normal skin microbiomes and to protect against pathogenic bacteria and fungi. ${ }^{2}$ Lack of skin acidity promotes the activity of fecal enzymes such as protease and lipase, which may irritate the skin. An increase in $\mathrm{pH}$ value may demonstrate disruption in skin barrier function, leading to various pathologic skin conditions, most commonly irritant diaper dermatitis. ${ }^{3}$ The effect of diaper use towards skin barrier function measured by $\mathrm{pH}$ has not yet been studied in a tropical country such as Indonesia, that has different humidity and temperature range compared to other non-tropical countries. A study to compare the $\mathrm{pH}$ values between diaper and non-diaper area is necessary to strengthen the pathophysiology of skin barrier changes due to diaper use, especially in a tropical country.

\section{Materials and Methods}

The purpose of this study is to compare the difference of $\mathrm{pH}$ value between infant's diapered and non-diapered skin. This crosssectional study was performed in the Department of Dermatology and Venereology, Dr. Soetomo Hospital, Surabaya. Consecutive sampling was done since December 2016, and 43 healthy babies who met inclusion criteria were selected. The inclusion criteria are infants aged 6-12 months, using specific disposable diapers daily, and parents consenting to the study. Samples were excluded if history of topical use of moisturizer, corticosteroids, antibacterial, or antifungal within 24 hours of examination were found; and if there were skin lesions on the examination area.

After signing informed consent, identity taking and anamnesis were done towards each sample. Skin examination was done at the buttocks, representing diaper area, and at the outer thigh, representing non-diaper area. The skin was dried with tissue paper, then each sample was acclimatized for 15 minutes before $\mathrm{pH}$ measurement. The measurement was performed using $\mathrm{pH}$-meter 3 times at each area, 5 seconds each time with 5 seconds interval, by one doctor, in a room with no direct air movement and no direct sunlight. The $\mathrm{pH}$ values were noted and analyzed statistically by SPSS for Windows.

\section{Results}

This study was performed in 43 healthy infants, with $53,5 \%$ male and $46,5 \%$ female, and $23,3 \%$ of the sample was 6 months old. Anamnesis revealed that 51,2\% of the sample usually have their diaper changed less than 6 times per day, and $48,8 \%$ more than 6 times per day. As for daily skin care routine before diaper change, most parents $(53,5 \%)$ cleaned the diaper area using baby wipes alternating with soap, $18,6 \%$ used only baby wipes, $16,3 \%$ used only soap, and $11,6 \%$ used water. Therefore, from 43 samples, 69,8\% used soap to clean diaper area. The type of soap used most frequently was liquid baby soap $(70,0 \%), 26,7 \%$ used bar baby soap,
Correspondence: Nadia Wirantari, Department of Dermatoveneorology, Medicine Faculty of Airlangga University/Dr. Soetomo Hospital, J1. Mayjen Prof. Dr. Moestopo No 6-8 Surabaya 60131, Indonesia. Tele.: 031.5501609.

E-mail: nadiawirantari@yahoo.com

Key words: $\mathrm{pH}$, infant's skin, diaper area, nondiaper area.

Contributions: All authors contributed equally.

Conflict of interest: The authors declare no potential conflict of interest.

Funding: none

Received for publication: 1 February 2019. Accepted for publication: 13 February 2019.

This work is licensed under a Creative Commons Attribution-NonCommercial 4.0 International License (CC BY-NC 4.0).

(C) Copyright N. Wirantari et al., 2019

Licensee PAGEPress, Italy

Dermatology Reports 2019; 11(s1):8056

doi:10.4081/dr.2019.8056

and 3,3\% used bar antiseptic soap. Moisturizer was applied in $25,6 \%$ sample after each diaper change, and the type most frequently used was cream based $(54,5 \%)$. The application of talc or powder was performed in $18,6 \%$ sample after their daily diaper change. $46,5 \%$ of the sample was formula-fed, $37,2 \%$ was breastfed, and $16,3 \%$ was both breast and formula-fed. $95,3 \%$ sample was aterm (37-40 gestational weeks). History of diaper rash was denied in $48,8 \%$ sample. As much as $44,2 \%$ of the sample had history of atopy, with the most frequent manifestation being atopic dermatitis $(62,8 \%)$.

The measurement revealed mean $\mathrm{pH}$ value of diaper area was $6,11 \pm 0,72(95 \% \mathrm{CI}$, $4,88-8,02)$ and mean $\mathrm{pH}$ value of nondia-

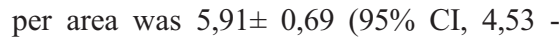
7,69). There is significant difference between $\mathrm{pH}$ value of diaper area and nondiaper area $(p=0,005)$, shown in Table 1 .

We also analyzed the $\mathrm{pH}$ values between diaper and non-diaper area against each variable in sex groups, age groups, frequency of diaper change, daily skin care routine, type of soap used, the use of moisturizer, powder, feeding history, birth gestational age, previous history of diaper rash, and atopy. It was revealed that the difference in $\mathrm{pH}$ values between diaper and nondiaper area against the different sex and age groups are not significant. There was no significant difference in $\mathrm{pH}$ values between diaper and non-diaper area against frequen- 
cy of diaper change $\geq 6$ times daily, but there was significant difference in frequency of diaper change $<6$ times daily $(6,36 \pm 0,36$ vs $5,97 \pm 0,76$, CI $95 \% \mathrm{p}<0,05)$. In daily skincare routine before diaper change, the use of soap or soap alternating with baby wipes increased the $\mathrm{pH}$ value of diaper area (soap $6,07 \pm 0,52$ vs $5,78 \pm 0,58$, CI $95 \%$ p $=0,03$ ) (soap alternating with baby wipes $6,18 \pm 0,78$ vs $5,89 \pm 0,64$, CI $95 \% \mathrm{p}=0,005)$. The use of only baby wipes and only water did not make significant difference in $\mathrm{pH}$ values, nor did the different types of soaps that were used. The use of moisturizer or powder after diaper change did not cause significant difference in $\mathrm{pH}$ value in diaper and non-diaper area. Being formula-fed increased $\mathrm{pH}$ value of diaper area significantly $(6,03 \pm 0,71$ vs $5,88 \pm 0,66$, CI $95 \% \mathrm{p}=0,04)$, whereas being breastfed or combination of breast- and formula feeding did not cause significant difference in $\mathrm{pH}$ values. History of atopy increased $\mathrm{pH}$ value of diaper area $(6,30 \pm 0,86$ vs $6,06 \pm 0,77, \mathrm{CI}$ $95 \% \mathrm{p}=0,03)$, whereas birth gestational age and previous history of diaper rash did not cause significant difference in $\mathrm{pH}$ values between diaper and non-diaper area.

\section{Discussion}

The samples in this study were healthy infants aged 6-12 months old. There was no significant difference in $\mathrm{pH}$ value of diaper and non-diaper area against the different sex or age group, in concordance with previous study by Giusti $\mathrm{F}$ et al. ${ }^{4}$ This shows that skin barrier function is not influenced by sex, and there is no significant difference in skin barrier function within the age of 6 to 12 months. With diaper change less than 6 times daily, $\mathrm{pH}$ value of diaper area was significantly higher than non-diaper area $(6,36 \pm 0,36$ vs $5,97 \pm 0,76$, CI $95 \% \mathrm{p}<0,05)$. $\mathrm{Li} \mathrm{CH}$ et al. revealed that infants with diaper change less than 6 times daily had a higher risk towards diaper rash compared to infants with daily diaper change 6 times or more. ${ }^{5}$ This is in concordance with our data analysis, that the frequency of diaper change had a significant role in diaper area skin barrier function. Diaper change in infants should be done every 4 hours, or 6 times or more daily. ${ }^{6}$ Prolonged occlusion in diaper area may increase $\mathrm{pH}$ value due to prolonged exposure of urine and feces. Ammonia from urine increases $\mathrm{pH}$ value,

Table 1. pH value analysis.

\begin{tabular}{lcc} 
Group & Mean & P \\
pH diaper area & $6,11 \pm 0,72$ & 0,005 \\
pH non-diaper area & $5,91 \pm 0,69$ & \\
\hline
\end{tabular}

thus increasing the proteolytic activity of fecal enzymes, which further disrupt skin barrier function.

In daily skincare routine before diaper change, the use of soap or soap alternating with baby wipes for cleansing increased the $\mathrm{pH}$ value of diaper area. The use of water and washcloth are often regarded as the golden standard for cleansing. However, the polar nature of water limits its ability to remove lipophilic substances from the skin and does not have any $\mathrm{pH}$ buffering action. ${ }^{7}$ Soaps usually have high $\mathrm{pH}$ value, especially bar soaps. Gfatter et al. found that regular liquid soap $(\mathrm{pH} 9,5)$ causes a higher $\mathrm{pH}$ value on infants' skin compared to $\mathrm{pH}$-buffered liquid soap $(\mathrm{pH} 5,5)$ and $\mathrm{pH}$ buffered bar soap $(\mathrm{pH} 5,5){ }^{8}$ Lavender $\mathrm{T}$ et al. reveals no significant difference in infants' skin $\mathrm{pH}$ value with the use of baby wipes compared to water and cloth for 4 weeks. ${ }^{9}$ The result of this study corresponds with previous studies, that prolonged use of soap causes higher $\mathrm{pH}$ value in diaper area. Different types of soap did not cause significant difference in $\mathrm{pH}$ value. However further study with a larger sample size is needed to determine the correlation between soap types and $\mathrm{pH}$ value, because only one sample used antiseptic soap in this study thus it could not be analyzed. Only $25,6 \%$ sample in this study used moisturizer before each diaper change, and $54,5 \%$ of which used creambased moisturizer. The use of moisturizer and the different types of moisturizer did not cause a difference in $\mathrm{pH}$ values on diaper and non-diaper area. Theoretically, cream-based moisturizers have protective effects on stratum corneum, enhancing maturation of skin barrier function, whereas lotions are less protective. ${ }^{6}$ Further studies with more controlled variables and a larger sample size is needed to determine the significance of moisturizer on skin $\mathrm{pH}$ value. Only $18,6 \%$ of the sample used talc before diaper change, with no significant difference on skin $\mathrm{pH}$. Talc is often used in baby skin care but does not protect the skin from urine and feces exposure, and the granules may further cause friction on irritated skin. ${ }^{7}$

In $46,5 \%$ of the sample that was formula fed, the mean $\mathrm{pH}$ value on diaper area was significantly higher than non-diaper area $(6,03 \pm 0,71$ vs $5,88 \pm 0,66$, CI $95 \%$ $\mathrm{p}=0,04)$. There is higher amount of protease and bile acid in the feces of formula-fed infants compared to breastfed infants, ${ }^{10}$ therefore, the $\mathrm{pH}$ of feces and diaper area of formula-fed infants are higher. From gestational age, there is no significant difference in $\mathrm{pH}$ values between diaper and non-diaper areas. The epidermis is fully formed in 34 weeks of gestation, therefore premature infants have less developed skin barrier compared to term infants. ${ }^{11}$ Preterm infants need longer time to complete postnatal adaptation and to reach term infants' skin barrier function, which may take around 4 weeks, depending on the gestational age at birth. ${ }^{12}$ In this study, gestational age did not cause any difference in the $\mathrm{pH}$ value at diaper and non-diaper area, because skin maturation occurs in the first month of life, whereas the samples of this study were 6-12 months old. No significant difference was found on diaper and non-diaper area against history or different frequency of diaper rash. Adalat $\mathrm{S}$ et al. shows that previous recurrent episodes of diaper rash do not predispose to current diaper rash. ${ }^{13}$ This supports our finding that no difference in $\mathrm{pH}$ value was found, which might be due to the complete healing of the skin after each episode of diaper rash.

In infants with history of atopy, $\mathrm{pH}$ value of diaper area is higher than non-diaper area $(6,30 \pm 0,86$ vs $6,06 \pm 0,77$, CI $95 \%$ $\mathrm{p}=0,03)$. In atopic skin, there is decreased filaggrin, which is the precursor of amino acids for maintaining acidic $\mathrm{pH}$ on the skin. The secretion of sweat high in lactic acids is also reduced in atopic patients, leading to higher skin $\mathrm{pH} .{ }^{14}$ In this study, history of atopy may further disrupt skin barrier function in diaper area, due to the decreased filaggrin and lactic acid. The measurement revealed that the mean $\mathrm{pH}$ value of diaper area was $6,11 \pm 0,72(95 \% \mathrm{CI}, 4,88-8,02)$ which is significantly higher than the mean $\mathrm{pH}$ value of non-diaper area which was $5,91 \pm 0,69$ (95\% CI, 4,53 - 7,69), $\mathrm{p}=0,005$. The normal $\mathrm{pH}$ value of the skin is $4,5-6 .{ }^{14}$ Bartels NG et al. demonstrated higher $\mathrm{pH}$ in diaper area compared to nondiaper area in healthy infants aged 9 months $(5,5 \pm 0,7$ vs $5,1 \pm 0,5$, CI $95 \% \mathrm{p}<0,001) .{ }^{15}$ Giusti $\mathrm{F}$ et al revealed that the $\mathrm{pH}$ value in infants aged 812 months old diaper area is higher than on volar area $(6,06 \pm 0,54$, vs $5,45 \pm 0,71$, CI $95 \% \mathrm{p}<0,05) .{ }^{4}$ These support our findings that $\mathrm{pH}$ value on diaper area is higher than non-diaper area, even though there is no visible skin lesion. Diaper area may have increased $\mathrm{pH}$ due to exposure of the accumulation of urine and feces. Ammonia from urine increases $\mathrm{pH}$ value, and the activity of proteolytic fecal enzymes, which may irritate the skin and decreases skin acidity.

\section{Conclusions}

The $\mathrm{pH}$ value of healthy infants age 612 months in diaper area is $6,11 \pm 0,72(95 \%$ $\mathrm{CI}, 4,88-8,02)$ and in non-diaper area is $5,91 \pm 0,69(95 \% \mathrm{CI}, 4,53-7,69)$. The $\mathrm{pH}$ value in diaper area is significantly higher than non-diaper area. 


\section{References}

1. Shende S. World baby diapers market, opportunities and forecasts, 2013-2020. Allied Market Research (Internet). Allied Market Research; 2014 (cited on: 27 June 2016). Cited from: http://www.alliedmarketresearch.com/b aby-diapers-market

2. Ward DB, Fleischer Jr. AB, Feldman SR, Krowchuk DP. Characterization of diaper dermatitis in the United States. Arch Pediatr Adolesc Med 2000; 154: 943-6.

3. Shin HT. Diaper dermatitis that does not quit. Dermatol Ther 2005;18:124-35.

4. Giusti F, Alessandro M, Laura B, Stefania S. Skin barrier, hydration, and $\mathrm{pH}$ of the skin of infants under 2 years of age. Pediatr Dermatol 2001; 18(2):93-6.

5. Li CH, Zhu ZH, Dai YH. Diaper dermatitis: a survey of risk factors for chil- dren aged 1-24 months in China. J Int Med Res 2012; 40:1752-60.

6. Ness MJ, Davis DMR, Carey WA. Neonatal skin care: a concise review. Int Journ Dermatol 2013; 52:14-22.

7. Adam R. Skin care of the diaper area. Pediatr Dermatol 2008;25(4):427-33.

8. Gfatter R, Hackl P, Braun F. Effects of soap and detergents on skin surface $\mathrm{pH}$, stratum corneum hydration and fat content in infants. Dermatology 1997. 195(3): 258-62.

9. Lavender T, Furber C, Campbell M, Victor S, Roberts I, Bedwell C et al. Effect on skin hydration of using baby wipes to clean the napkin area of newborn babies: assessor-blinded randomised controlled equivalence trial. BMC pediatrics 2012:12(59):1-9.

10. Yosipovitch G, Maayan-Metzger A, Merlob P, Sirota L. Skin barrier properties in different body area in neonates. Pediatrics 2000;106:105-8.

11. Hoeger PH, Enzmann CC. Skin physi- ology of the neonate and young infant: a prospective study of functional skin parameters during early infancy. Pediatr Dermatol 2001;19(3): 256-62.

12. Kalia YN, Alberti I, Sekkat N. Normalization of stratum corneum barrier function and transepidermal water loss in vivo. Pharm Res 2000;17:114850.

13. Adalat S, Wall D, Goodyear H. Diaper dermatitis- frequency and contributory factors in hospital attending children. Pediatr Dermatol 2007;24(5):483-8.

14. Ali MA, Yosipovitch G. Skin pH: from basic science to basic skin care. Acta Derm Venereol 2013; 93: 261-7.

15. Bartels NG, Lunnemann L, Strouts A, kottner jan, Serrano J, Blume-peytavi U Effect of Diaper Cream and Wet Wipes on Skin Barrier Properties in Infants: A Prospective Randomized Controlled Trial. Pediatr Dermatol 2014; 31(6): 683-91. 